\title{
POLICY OVERVIEW
}

\section{GU Mingyuan}

\section{On General Issues of Bilingual Education for Minority Ethnic Groups}

\begin{abstract}
Minority language literacy is an important issue in national education policy for any multi-nationality country. China sticks to the policy of safeguarding the rights and interests of ethnic minority groups to use their own languages and writing systems. In education, considering communications among different nationalities and the development of minority ethnic groups, a bilingual education policy is being implemented by insisting on teaching students in their own ethnic languages; when the mastery of their own languages has been achieved, bilingual teaching will be employed. There are three types of bilingual teaching for minority ethnic groups: teaching in their own languages, with Mandarin Chinese added; teaching in Mandarin Chinese, with minority languages added; teaching both in Mandarin Chinese and in minority languages. The biggest problems to be solved in implementing bilingual education in ethnic minority regions are the editing of language textbooks and supporting materials for minority ethnic groups and the training of ethnic minority teachers.
\end{abstract}

Keywords minority ethnic groups, minority language literacy, bilingual education

Language is a major element in the composition of ethnicity, as a vehicle for inheriting culture, and a communication tool among ethnicities. Ushinski, a famous Russian educator, paid special attention to ethnic languages and claimed in The Native Word that ethnic language is the most beautiful flower that initiates the whole spirit of an ethnicity from prehistory forward. It will never die, but

GU Mingyuan $(\square)$

International and Comparative Education Research Institute, Beijing Normal University, Beijing 100875, China

E-mail:mygu@sina.com 
rather will bloom over and over. He also stated that language is a relationship, one which is the most vital, abundant and strong. It has connected every ethnicity from the past to the present and future as a kind of historic and vital vector. It not only expresses ethnic vitality, but also reflects life itself. When an ethnic language vanishes, ethnicity also fades away (Constantinof, 1996, pp. 273-274).

The language issue has great significance to an ethnic group's existence and the relations among ethnic groups. Many conflicts in the present world are related to ethnic languages. For example, Quebec, a French-speaking region in Canada, has conflicts with English-speaking regions. Belgium is divided into Dutch-speaking and French-speaking regions. In 1968, student unrest took place at Leuven Catholic University where students occupied the university and shouted slogans saying "Walloons [Belgian people who speak French] should get out of Leuven." This event caused the resignation of the coalition government made up of the Catholic socialist party and the liberal progressive party. In 1970, Leuven Catholic University was officially split into two independent universities whose teaching languages were Dutch and French accordingly (Gu, 1992, p. 249). We can also see the influence of the language issue in today's political crisis in Ukraine. Therefore, developing ethnic languages is an important concern in educational policies for ethnic groups, and an important aspect of governments' policy towards minority ethnic groups. In his essay, "Some Critical Views on Ethnic Issues," Lenin mentioned that having taken the above two trends into consideration, the basic principles of Marxism on ethnic relations firstly consist of ethnic equality and language equality, allowing no privileges or entitlements to any ethnic groups, and secondly that internationalism must be adhered to (Lenin, 1959, p. 219).

However, in a multi-ethnic country such as China, how to properly deal with the relationship between the national language and the languages spoken by minority ethnic groups is a complicated issue. Members of minority ethnic groups need to learn their own language if they are to protect their cultural traditions, but to develop their regional economy and increase communication with other groups, they also have to learn the national language in order to integrate themselves into the greater family of Chinese ethnic groups. It is particularly necessary for minority ethnic groups in remote mountainous areas to learn the national language even as a foreign language since they are eager to develop their economy. Therefore, it is of great importance to implement 
bilingual education in the minority ethnic areas.

\section{The Current Situation of Minority Ethnic Groups and the Policy on National Language in China}

China is a multi-ethnic country. While the Han nationality accounts for 91.59 percent of the country's population, there are also 55 minority ethnic groups comprising the large and diverse country. These minority ethnic groups are very different in their respective populations. According to the fifth nationwide census, there are only two minority ethnic groups whose populations number is more than 10 million: the Zhuang nationality and the Manchu nationality. There are seven minority ethnic groups with a population of over five million, nine with over one million, four with over 500,000 and thirteen with fewer than 500,000, including some minority ethnic groups comprising of fewer than 10,000 people (National Bureau of Statistics of the People's Republic of China, 2000). Although many minority ethnic groups have small populations, they are widely distributed and their living areas cover $50 \%-60 \%$ of the whole country. These minority ethnic groups are located in different provinces and regions, such as the Inner Mongolia autonomous region, the Xinjiang Uighur autonomous region, the Tibetan autonomous region, the Guangxi Zhuang autonomous region, the Ningxia Hui autonomous region, Heilongiiang province, Liaoning province, Gansu province, Qinghai province, Sichuan province, Yunnan province, Guizhou province, and Taiwan. Most people belonging to ethnic minorities live in mountainous areas, plateaus, pastures and forest areas. There are also more than one million people of minority ethnicity scattered in towns and villages all over the country.

Among the 55 minority ethnic groups, the Hui and Manchu nationalities speak the same language as the Han majority: Mandarin Chinese. The other 53 nationalities use their own languages. Among these ethnic languages, there are 29 ethnic languages that belong to the Sino-Tibetan family of languages, and they are mainly distributed in the Central South and Southwest regions of China; there are 17 ethnic languages which belong to Altai language family, and they are mainly distributed in the Northeast and Northwest regions of China; there are two ethnic languages which belong to the Indo-European language family. The language of the Gaoshan nationality belongs to Southern Island languages, and 
there is one ethnic language for which there is currently no conclusive explanation as to its family (State Council Information Office of the People's Republic of China, 2009).

Before 1949, there were only 21 minority ethnic groups with their own written script. Some of them used original pictographic ideograms, some used syllabic languages, and some used alphabets. After the founding of the People's Republic of China, from 1950 to 1958, the Central Government of the People's Republic of China successively helped the Zhuang, Buyi, Miao, Yi, Dong, Hani, Lisu, Va, $\mathrm{Li}$, and Naxi nationalities establish written languages which were based on the Roman alphabet, and at the same time, the Uyghur, Kazakh, Jingpo, Lahu and the Dai nationalities were assisted to reform their written languages (Ethnic Minorities in China Editing Board,1981, pp. 1-25).

China has a policy of regional autonomy which is fully implemented. In ethnic minority areas, China has established autonomous regions, autonomous prefectures and autonomous counties even for some areas where ethnic populations do not account for the majority of the local population. China has five provincial autonomous regions, 30 autonomous prefectures and 129 autonomous counties.

Following the Marxist principle of national policy, China insists on safeguarding minority rights to use their own languages and writing systems. The Common Program of the 1st Chinese People's Political Consultative Conference states that every minority has the freedom to develop their language and keep or change their customs and habits, and religious beliefs. This point has been reiterated consistently in the Chinese Constitution. In 1982, The Fifth National People's Congress passed The Constitution of the People's Republic of China in which it states that every nationality has the freedom to use and develop their languages and writing systems, keep or change their habits and customs. To practice the new regulations, autonomous regional governments take the native spoken and written language as their main opportunity to perform their duty to ethnic minorities. Citizens of all nationalities shall have the right to use their native language to exercise their legal rights. In the minority ethnic inhabited or mixed multi-ethnic regions, the local written language is used for public documents. It will be respected to use native languages in daily life or social interactions. The national language policy reflects basic principles of Marxism in dealing with ethnic issues. It also represents the common interests of all ethnic 
groups and shows the spirit of our country to respect minority ethnic groups including their culture and to promote the development of minority ethnic groups.

In education, for the communication and development of minority ethnic groups, a bilingual educational policy is carried out in minority ethnic regions.

\section{A Summary of the Types of Implementation of Bilingual Teaching}

Bilingual teaching refers to the use of the national common language alongside ethnic languages in teaching. In China, it refers to teaching in ethnic mother tongues and Mandarin Chinese.

China's bilingual teaching policy is to stick to the use of ethnic literacy in teaching and the development of bilingual teaching on the basis of a solid ethnic literacy. At the First National Conference on ethnic education, it was clearly pointed out that for ethnic groups that have their own common language, ethnic literacy should be used in primary and middle school while Mandarin Chinese classes are provided on demand and if desired. However, in implementation, approaches should be adopted according to the specific situation. In regions where ethnic language is commonly used in daily communication among common people, all subjects at school should be taught through ethnic literacy, while Mandarin Chinese is generally taught from the higher level in primary school; if some students are already used to using Mandarin Chinese and do not know how to use ethnic languages, they can be taught in Mandarin Chinese in separate classes, with ethnic literacy being taught in addition. In regions where Mandarin Chinese is commonly used in daily communication among most people, and ethnic languages are not used, then Mandarin Chinese literacy is the main teaching language with ethnic literacy being taught in addition; if some students have difficulty using Mandarin, they can be taught ethnic language literacy in a separate class or with assisted teaching.

Developing bilingual teaching in minority ethnic regions is of great value for the development of minority ethnic groups' education and for the improvement of the scientific and cultural level of the whole nation. The economy, society and education of Han nationality regions are generally better than those of minority ethnic regions. Chinese literacy in minority ethnic groups is beneficial to the 
communication among different ethnic groups and to the acceptation of comparatively advanced science and technology. Therefore, the Laws on Regional National Autonomy of the People's Republic of China stipulate that schools which mainly admit minority ethnic students should have Chinese literacy courses for the upper grades of primary school and middle school students are encouraged to speak Mandarin Chinese (Central Government of the People's Republic of China, 2005). In 1994, Ministry of Education issued The Full-Time National Primary and Middle School Chinese Language Syllabus and pointed out that, in the long development process of history, Chinese literacy had already became the common language of different ethnic groups. Chinese literacy in minority ethnic groups is of great significance for the development of both science and culture in minority ethnic groups, for the cultivation of minority ethnic talent, and for the reinforcement of association among different ethnic groups (Gu, 1992, p. 136).

There are mainly three types of bilingual teaching in minority ethnic groups: the first one involves primarily teaching in the local language, in addition to Chinese literacy; the second one involves teaching primarily in Chinese, in addition to ethnic language literacy; the third one is that some courses are taught in Chinese and some in the ethnic language. But a variety of modes have emerged from these three types according to different circumstances in different regions. For example, ethnic language literacy teaching is adopted for primary schools, but Chinese is used in middle schools in some cases. The Chinese literacy programs begin at different ages in different regions where ethnic langue literacy is taught in schools. For example, the first two types are mainly used for bilingual teaching in the Inner Mongolian Autonomous Region where second language literacy is generally begun in Grade 2 of primary schools. There are many different bilingual teaching modes in the Qinghai-Tibet region, with each mode depending mainly on the local language conditions and the students' willingness to learn.

\section{Problems in Developing Bilingual Education in Minority Ethnic Areas}

Two prominent problems in developing bilingual education in minority ethnic group areas are the lack of teaching materials and the lack of teachers. 
To solve the problems of teaching materials, the 1959 National Minority Ethnic Group Publishing Conference established a regulation that every middle school and normal school should use national standard textbooks, but in addition these schools should adopt self-edited minority materials as supplementary teaching aids (Gu, 2012, pp. 2540-2541). From then on, Inner Mongolia, Jilin, Qinghai, Xinjiang, Sichuan, Yunnan, and Guangxi provinces and autonomous regions have set up special organizations dedicated to editing and publishing materials in ethnic languages. These organizations have edited and published basic teaching materials in 17 ethnic languages and the materials are commonly used in elementary and middle schools, technical secondary schools and institutions of higher education. Among these organizations, Yanbian Education Publishing House in Jilin Province was the earliest, established in 1947.

However, there are several problems in the compiling of ethnic literacy teaching materials and the translation and publication of general teaching materials. The first difficulty is that there are few translators who not only know two languages, but also have subject knowledge. This makes it difficult to translate national general teaching materials into teaching materials in the languages of minority ethnic groups. Besides, the inconsistency of some translations results in difficulties in study. The second problem in national general teaching materials is that of adaptation to different localities. It is difficult for minority peoples to understand some content in general teaching materials due to different modes of thought and conception between ethnic minority and the Han nationality regions. For example, there are no concepts such as "zero" or "minus" (see Luo, 2008) in some languages so this has to be considered in the compiling of teaching materials. The third difficulty is the lack of materials and resources necessary to support teaching. It is currently a burning question to solve the lack of national teaching materials as well as supplementary teaching materials.

The second problem concerning bilingual teaching is the teaching faculty. The Chinese Communist Party and government pay much attention to the formation of teaching staff for minority ethnic groups. In 1941, an Institute for Nationalities was built in Yan'an to cultivate cadres of minority ethnic groups. After the founding of the People's Republic of China, on 24 November 1950, the 10th Executive Meeting of the Central People's Government Administration Council approved the Pilot Program for Cultivating Ethnic Minority Leaders and the 
Pilot Program for Planning and Building a Central Institute for Nationalities and achieved a decision to build the main campus in Beijing and additional branches respectively in the Northwest, Southwest and Central South. From 1950 to 1958, more than 10 nationality colleges had been set up in the northwest, southwest and central south, Guizhou, Yunnan, Guangdong, Guangxi, Qinghai and Tibet. In 1984, Northeast University for Nationalities and The Second Northwest University for Nationalities were built and in the same year, West Hubei University was rebuilt and renamed Hubei Institute for Nationalities. In addition to cultivating ethnic minority leaders for the Party and government departments, most of these universities were training minority teachers. Minority teachers' colleges and teacher-training colleges were widely set up in minority areas for training minority teachers. Except for setting up special institutes to cultivate minority teachers, normal universities also enroll minority students. Beijing Normal University and East China Normal University and other normal universities attached to the Ministry of Education have set up special classes, such as the "Xinjiang Class" and the "Tibet Class," to cultivate qualified minority teachers. Meanwhile, provinces and cities also send Han teachers to minority areas regularly, to support education. In spite of this, teachers in minority ethnic areas are still in short supply, especially bilingual teachers, who are required to be equipped with not only disciplinary knowledge but also the mastery of a minority language and the national language, Mandarin Chinese. Teachers of the Han nationality who teach in minority schools, in my view, should also be acquainted with the local culture, customs and habits so as to be integrated with the minority people. Therefore, training minority teachers is an important step to implementing national education policies.

This overview of the policy of bilingualism in the education of minorities in China gives some insight into the complexity of issues that arise in a country with such a large and diverse population.

Acknowledgements This study is funded by 2010 National Science Education Programs (No.ADA100008). The author is grateful for the translation by Dr. Yao Zhenjun.

\section{References}

Central People's Government of the People's Republic of China. (2005). 中华人民共和国民 族区域自治法 [Regional autonomy law of the People's Republic of China]. Retrieved April 
22, 2014, from http://www.gov.cn/test/2005-07/29/content_18338.htm

Constantinof, H. A. (1996). 苏联教育史 [History of education in the Soviet Union] (Wu Ying, Trans.). 北京, 中国: 商务印书馆 [Beijing, China: The Commercial Press].

Ethnic Minorities in China Editing Board. (1981). 中国少数民族 [Ethnic minorities in China]. 北京，中国: 人民出版社 [Beijing, China: People's Publishing House].

Gu, M. Y. (Ed.). (1992). 教育大辞典 (第 12 卷) [The dictionary of education] (Vol. 12). 上海, 中国: 上海教育出版社 [Shanghai, China: Shanghai Educational Publishing House].

Gu, M. Y. (Ed.). (2012). 中国教育大百科全书 (第 4 卷) [Chinese encyclopedia of education] (Vol. 4). 上海, 中国：上海教育出版社 [Shanghai, China: Shanghai Educational Publishing House].

Lenin. (1959). 列宁论国民教育 [Lenin's education theory]. 北京, 中国: 人民教育出版社 [Beijing, China: People's Education Press].

Luo, Y. C. (2008). 侗族数学文化中的 2 与 $1 / 2$ 及相关计算 [2 and $1 / 2$ related calculations in the math of Dong nationality]. 凯里学院学报 [Journal of Kaili College], 26(3), 13-15. doi: 10.3969/j.issn.1673-9329.2008.03.005

National Bureau of Statistics of the People's Republic of China. (2000). 第五次人口普查数 据 (2000 年) [Fifth national population census of the People's Republic of China, 2000]. Retrieved April 21, 2014, from http://www.stats.gov.cn/tjsj/ndsj/renkoupucha/2000pucha/ $\mathrm{html} / \mathrm{t} 0201 . \mathrm{htm}$

State Council Information Office of the People's Republic of China. (2009). 中国的民族政策 与各民族共同繁荣发展 [Ethnic policy and common prosperity and development in China]. 北京, 中国: 人民出版社 [Beijing, China: People's Publishing House]. 